\title{
Synthesized Multilayer Power Converter for Wind Power Energy Conversion
}

\author{
Gundala Srinivasa Rao, V. Sathish
}

\begin{abstract}
Regardless of wind turbines has been delivered an unmistakable fuel source and does not taint the air like power plants that depend on ignition of petroleum products, for example, coal or gaseous petrol, since wind is a fluctuating wellspring of vitality it has encountered high order harmonics and isn't fit to meet the base burden vitality request. This situation powers wind turbine generator framework to have a power molding circuit called control converter that ought to be gauge of altering the generator recurrence and voltage to network however existing converters are fighting with low request music just so when high request sounds happens, there is a debasement in power quality and wind turbine need single multi arrange converter. As to issue, this work introduced a multi request consonant remover dependent on integrated multilayer control converter which dodges high symphonious mutilation so as to overhaul the power nature of wind based power plant by considering the accompanying properties that incites sounds, for example, control misfortune to adapt up to this bridge type rectifier is utilized, blame current that is amended by blame current limiter and the high recurrence part that is controlled utilizing nonlinear inductor lastly commotion is decreased by fell c type channel so this framework can fight with the high consonant contortion and kept up the influence quality and the transient steadiness of the wind turbine.
\end{abstract}

Key words: Bridge type rectifier, Fault current limiter, nonlinear inductor, cascaded c-type filter

\section{INTRODUCTION}

The worldwide power utilization is expanding and there is a more prominent interest on power generation and usage of vitality. Various sustainable power sources exist, for example, wind vitality, sun based vitality, wave vitality and hydro-control vitality. Among those, wind vitality is the quickly developing innovation as a standout amongst the most practical approaches to create power from sustainable power sources [1]. The breeze vitality transformation framework (WECS) comprises of a few parts, for example, mechanical, electrical and control framework. This will change over wind motor vitality into electrical vitality [2][3]. The breeze turbine framework comprises of a turbine rotor, a rigging box, a generator, a power electronic framework and a transformer for network association. Wind turbines catch the power from wind and convert it into mechanical vitality. Amid high wind speeds, it is imperative to control and restrict the changed over mechanical power. The generator changes over mechanical power into electrical power, which is sustained into a network conceivably through a power

Revised Version Manuscript Received on August 19, 2019.

Dr. Gundala Srinivasa Rao, Associate Professor of EEE, CMR College of Engineering \& Technology, Hyderabad, Telangana., India

Dr. V. Sathish, Asst. Professor of EEE, GATE Engineering College, Kodad, Telangana India. convertor and a transformer [4] [5] [6].

The power electronic change innovation assumes an essential job in disseminated age and reconciliation of sustainable power sources electronic matrix. The power electronic change framework can be ordered into $\mathrm{AC}$ to $\mathrm{DC}$ (rectifier), AC to DC (invertor), DC to DC convertor and AC to $\mathrm{AC}$ convertor. The power convertor is an interface between the generator and the brace. [7][8]. Power electronic convertor comprises of a heap/source, a power convertor and a control unit. A convertor may permit current stream in the two headings dependent on the topology and applications [9]. The info AC control at a fixed recurrence and voltage is changed over into a yield control at variable recurrence and voltage by utilizing static circuits called control convertors [10] [11][12]. Power electronic circuits can change over various $\mathrm{AC}$ or $\mathrm{DC}$ control sources to various $\mathrm{AC}$ or $\mathrm{DC}$ control loads. Likewise it contains control semiconductor gadgets, for example, switches, inductor and capacitor. A controller is utilized to work those changes as indicated by the predefined calculation and actualize unpredictable and propelled calculations [13] [14]. The power hardware can improve the quality and execution of the breeze control age framework with the approach of intensity semiconductor gadgets, delicate attractive materials with high attractive immersion motion thickness, limiting harmonization [15].

Multi-port converters (MPCs) are an alluring choice to interface with various sources and loads, for example, the previously mentioned sun based PV-battery fueled framework. Each associated source or burden is viewed as a port [16]. As contrasted and the customary methodology of one converter for each uni-directional power stream between two ports, MPCs consolidate a few converter circuits associated with each port into a bi-directional converter exchanging cell for each port [17]. These exchanging cells at that point structure a solitary power converter, through which all ports are associated by means of a transitional voltage transport or current transport. In many structures, the MPCs guarantee a solitary power handling stage between any two ports, henceforth they offer high transformation productivity and conservative converter plan [18-24].

The wind energy conversion system is used to change over wind vitality into electrical vitality utilizing power transformation framework. Power transformation accepts a vital part in trading the variable recurrence $\mathrm{AC}$ current into required network voltage. Wind control age can influence the power system quality due to the vulnerability of wind vitality 
nature and voltage hang. Since the breeze speed is varying with time to time it is unusual and the torque is evolving. In a couple of events the breeze speed will build/decline, which will influence the voltage of the DC interface. Exactly when the traded voltage is more than the limit of the dc-connect, exchanging misfortune will happen. By diminishing the exchanging misfortune, the influence converters effectiveness will be improved and lead to the cooling state of IGBT diodes. Furthermore, when the RMS voltage stream diminishes between 10 to 90 percent of the ostensible voltage stream, voltage droop happens. Voltage list will disengage the power between the breeze turbine and matrix. This will influence the nature of the power. So prerequisite ought to be obliged the present stream, anyway faultoccurs.

To keep up the present stream amid insufficiency or at variable wind speed, energystorage system is set at the dc link. The energy storage system self discipline balance at the dc link, anyway the surge of current is low. In any case, setting a energy storage will prompt extra cost and builds the framework multifaceted nature. Subsequently there will be increment need to recognize the consonant mutilation and the upkeep in power quality with transient dependability and the high recurrence varieties for supporting such target we are running for the system with multilayer Power converter improved which is been clarified in the accompanying portrayal.

\section{SYNTHESIZED MULTILAYER POWER CONVERTER}

The wind energy conversion system is utilized to change over wind vitality into electrical vitality utilizing power transformation framework which assumes an imperative job in exchanging the variable recurrence AC flow into wanted network voltage. In any case, these change frameworks did not adapt to the accompanying circumstances with the end goal that Wind control age can influence the power framework quality because of the vulnerability of wind vitality nature and voltage list. Since the breeze speed is fluctuating with time to time it is flighty, shifting torque will be delivered. In certain events the breeze speed will build/decline, which will influence the voltage of the DC link. At the point when the exchanged voltage is more prominent than the limit of the dc-interface, high music contortion is happening. In addition, since the vast majority of the converter utilizes nonlinear parts, for example, the semiconductor switches, and direct responsive segments, for example, the inductors, transformers and capacitors for halfway vitality stockpiling just as present and voltage sifting; the size, weight and cost of the converter are to a great extent expanded consequently this prompts corruption in power quality just as less transient security. In this manner, so as to adapt up to the above circumstances, this work is for the most part concentrating on structuring a vigorous converter which can oversee consistent voltage, low sounds mutilation and acquiring steady ideal transient dependability.

Therefore, the Wind Power Generation contrasted with the other sustainable power sources has created at a quick pace. Like the majority of the regular Power plants, Wind Power plants must guarantee the nature of intensity conveyed to the framework. Music are the most vital Power Quality Issues identified with the Wind Power plants which happen because of incessant exchanging of the Power Converters and variable Wind speed. Subsequently, this work has proposed a multi request consonant remover dependent on orchestrated multilayer control converter which keeps away from high symphonious mutilation so as to redesign the power nature of wind based power plant. Since this framework has considered the accompanying criteria control misfortune, blame current and the high recurrence segment, this framework can battle with the high symphonious bending and kept up the influence quality and the transient solidness of the wind turbine.

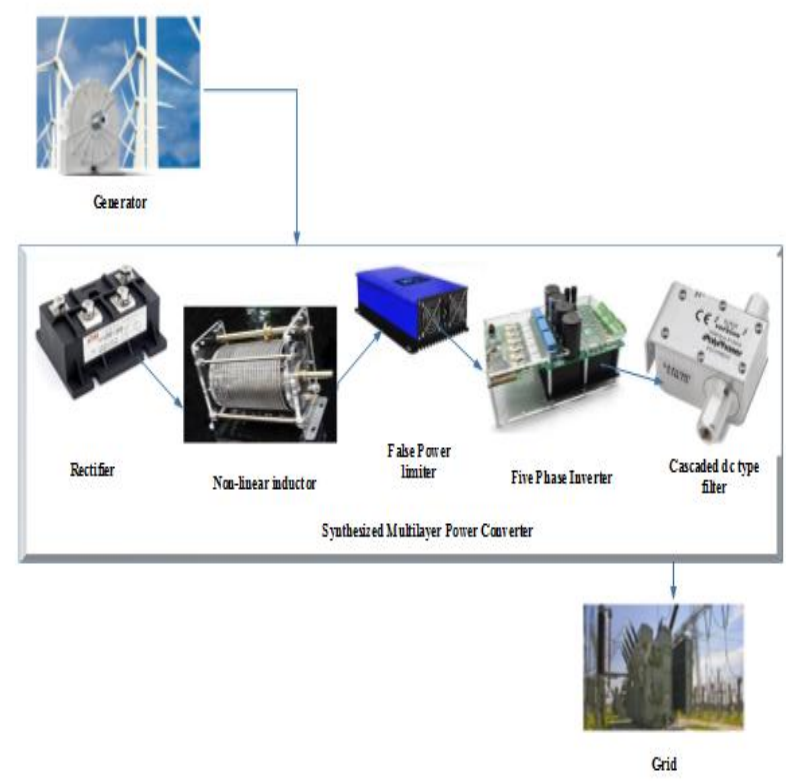

Fig 3.1: The flow diagram of the proposed system

At first elective current from the plant would be changed over into direct current with no power misfortune utilizing rectifier dependent on scaffold type thenin request to hinder the high recurrence part in the direct currentnonlinearinductoris adjusted. In this way false current is expelled by fusing Fault Power limiter. In the wake of being evacuated the blame just direct current is allowed to the five stage inverterto incognito the immediate current into the elective current. At long last, in the wake of being changed over into elective current it would have encountered sounds so as to expel that fell $\mathrm{c}$ type channel is adjusted. By along these lines the proposed framework has accomplished better power quality. Along these lines the working instrument of every part of the Synthesized Multilayer Power Converter is been depicted and as an activity the Wind Source of Input is considered for the procedure. The Source of Input is being is considered to the procedure by methods for Wind collecting through turbines.

\section{RESULT AND DISCUSSION}

In this exploration work, the recreations of Permanent Magnetic Synchronize Generator (MSG) with multi request symphonious remover dependent on orchestrated multilayer control converterfor therenewable breeze control frameworks are displayed. Reenactments have been finished utilizing MATLAB' Simulink. 


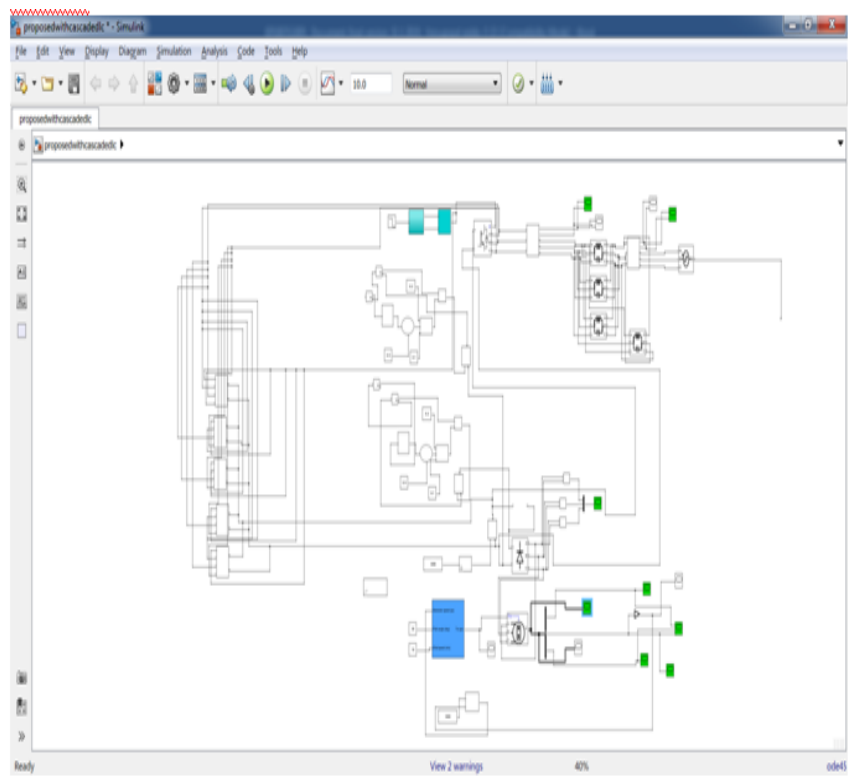

Fig: 3.1 Preview Design for the Proposed Model

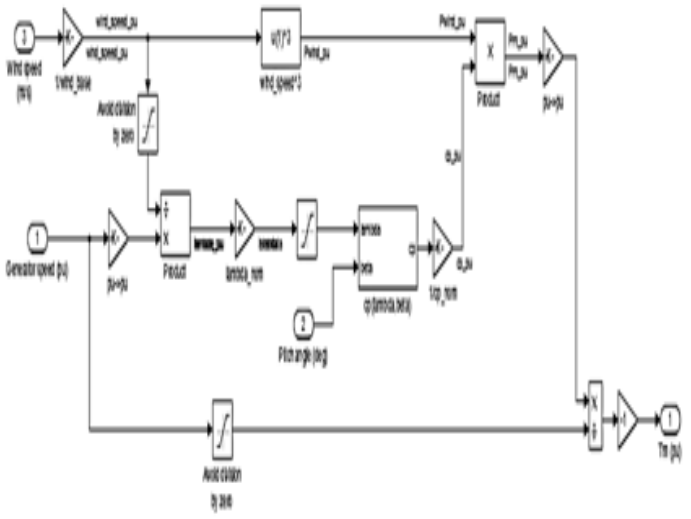

Fig: 3.2 Simulink model for wind turbine

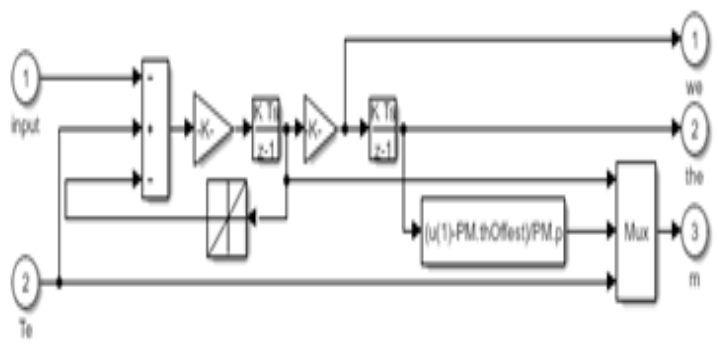

(1) 0

Fig 3.3 Simulink model for Mechanical part of PMSG

A Permanent Magnet Synchronous Generator is where the excitation field is given by a perpetual magnet rather than a curl. The rotor contains the perpetual magnet and the stator is the stationary armature that is electrically associated with a heap.

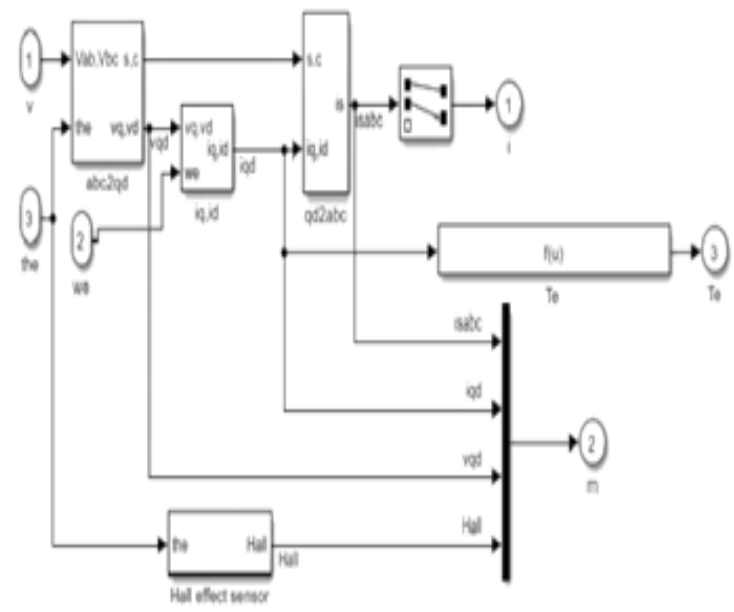

Fig 3.5 Simulink model for electrical part of PMSG

The stator attractive field shows up as a consistent pivoting field and twists at a similar recurrence as the rotor when the rotor contains a solitary dipole attractive field. The two fields move in 'synchronicity' and keep up a fixed position w.r.t each other as they pivot. The armature mmf consolidates ectopically with the tenacious transition of the lasting magnets, which prompts higher air-hole motion thickness and in the long run center immersion. In PMSG, the yield voltage is corresponding to the speed.

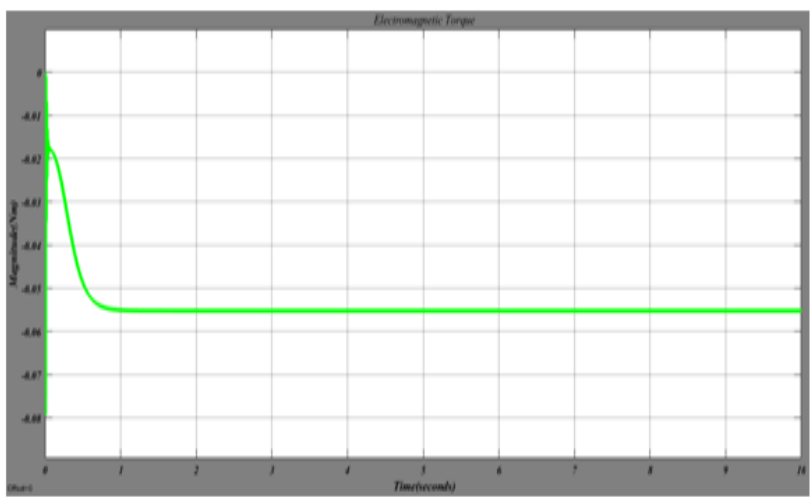

Fig 4.6 Mechanical Torque (Tm (pu)) of the Wind Turbine.

The below figure shows the results of permanent magnet synchronous machine

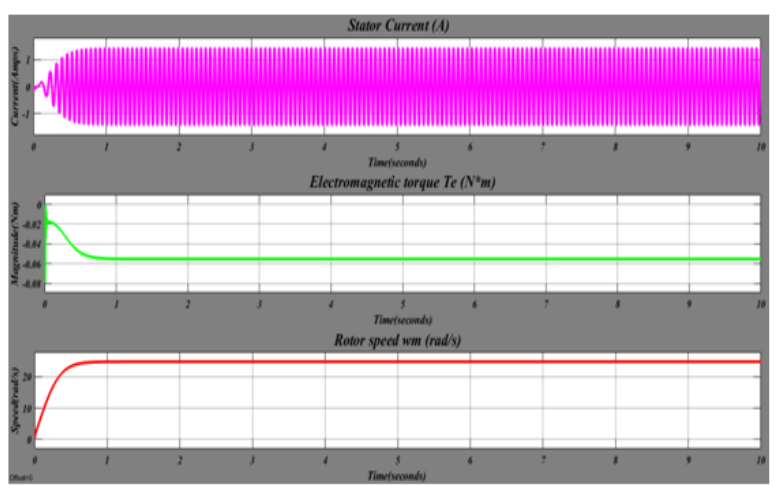

Fig: 4.7Output of Stator Current, Electromagnetic torque and Rotor speed PMSM

Published By: 


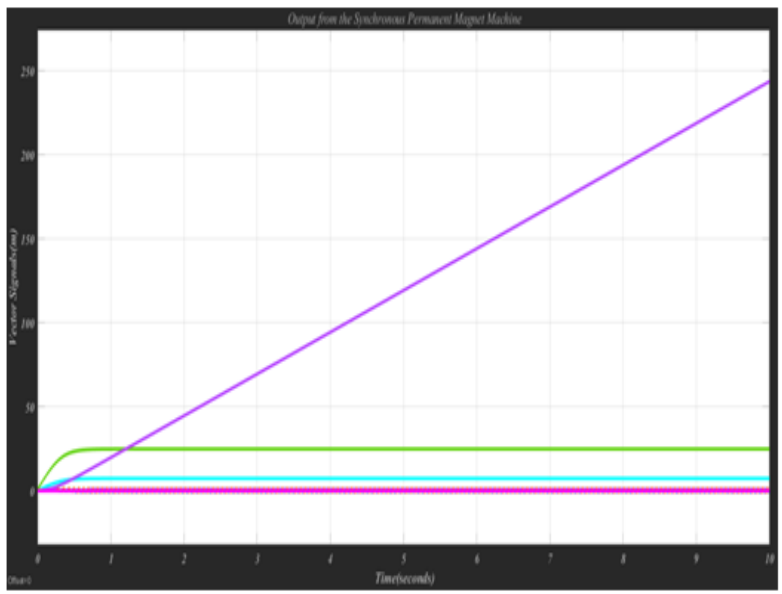

Fig: 4.8 Output of magnitude from the Synchronous Permanent Magnet Machine.

Single phase fault current limiter:

This performs limiting current fault arising in the phases; the table shows the current limited

values;

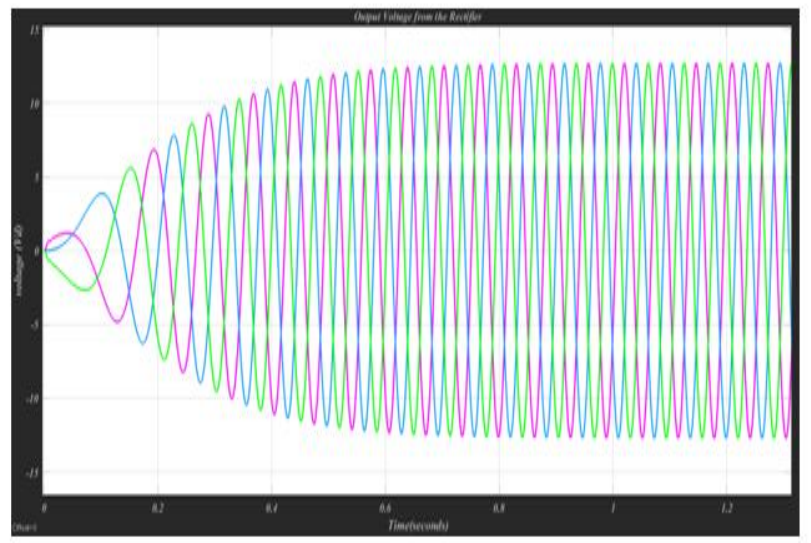

Figure: 4.9 Output of current limited during faults

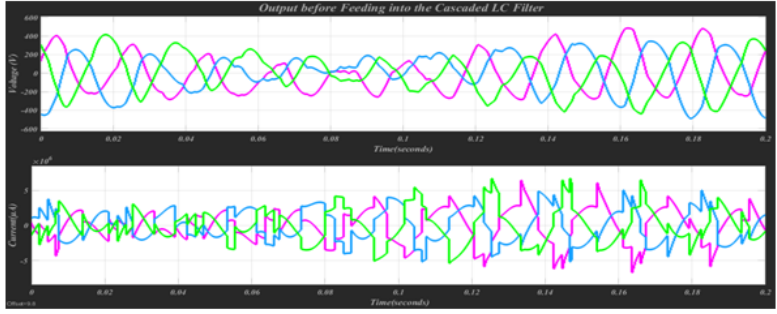

Fig: 4.10Outputs before Feeding into the Cascaded LC Filter

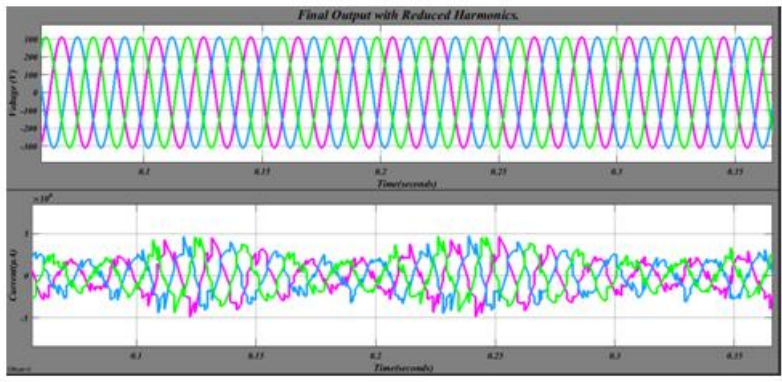

Fig: 4.11 Output with Reduced Harmonics

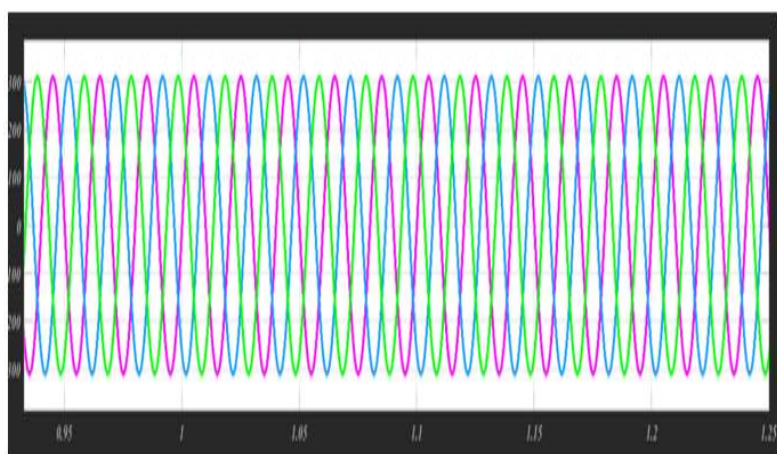

Voltage output with transformer

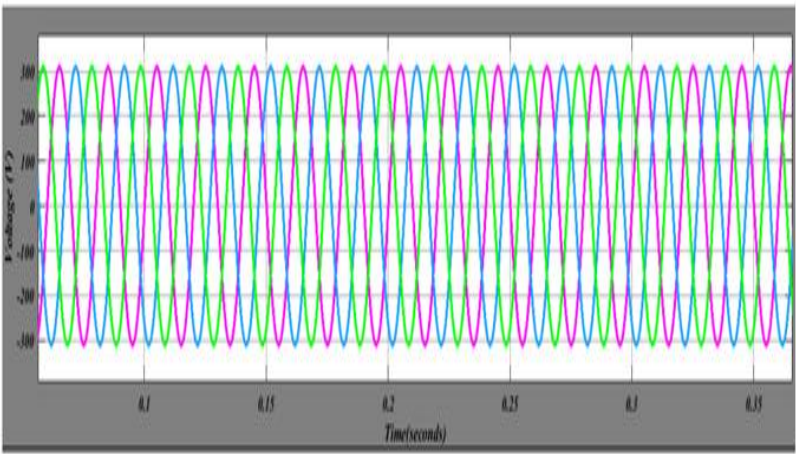

Voltage output without transformer [proposed]

Fig 4.12 shows the voltage stability for the existing and the proposed

The above demonstrates the resultant diagram got because of not utilizing transformer. The outcome demonstrates that voltage diagram acquired is in standard with, not utilizing transformer.

\subsection{Performance measure}

To demonstrate the adequacy of the proposed model, the accompanying areas manages examination with different techniques

As far as power misfortune:

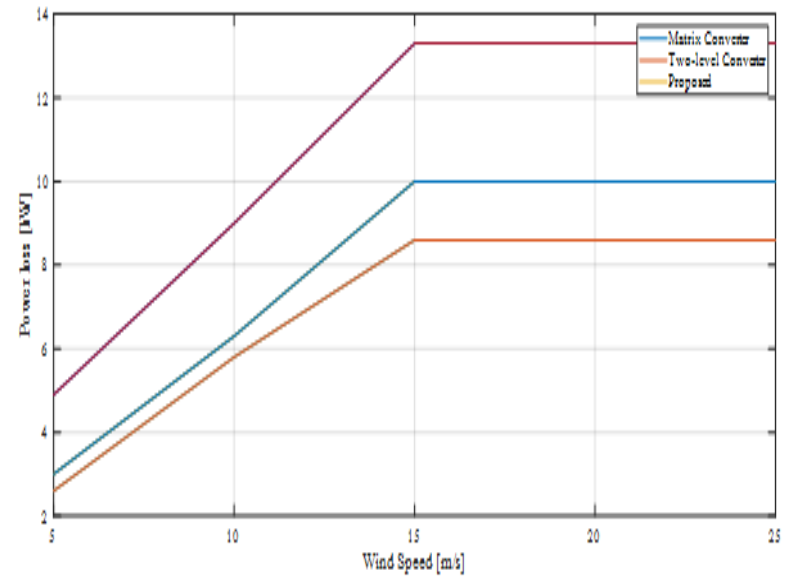

Fig: 4.12 Comparison of Power loss with existing converters to proposed.

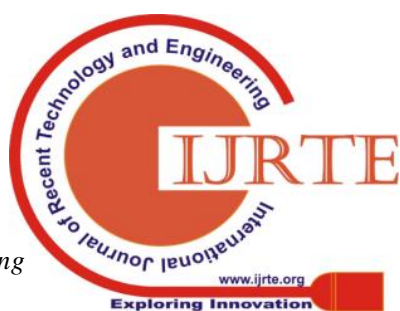




\begin{tabular}{|c|c|c|}
\hline Matrix converter & Two level converter & Proposed \\
\hline 4.9 & 3 & 2.6 \\
\hline 9 & 6.3 & 5.8 \\
\hline 13.3 & 10 & 8.6 \\
\hline 13.3 & 10 & 8.6 \\
\hline 13.3 & 10 & 8.6 \\
\hline
\end{tabular}

Table 4.13: Values for the comparison of Power loss with existing converters

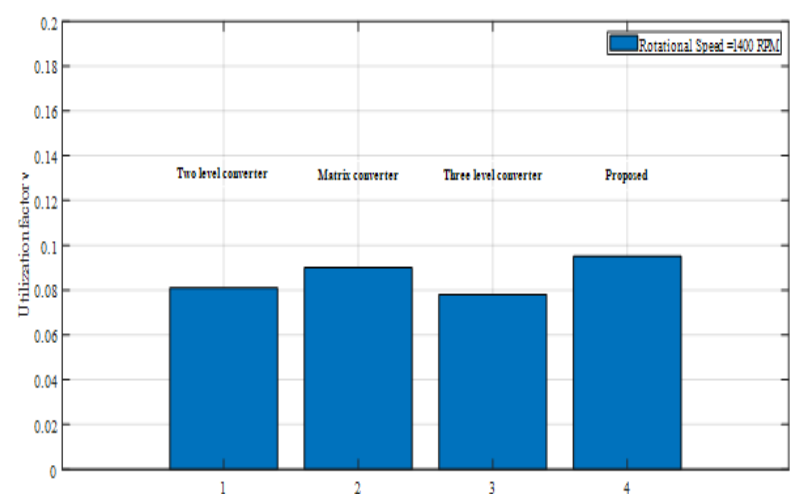

Fig: 4.13 Comparison of Utilization Factor with existing converters Vs proposed.

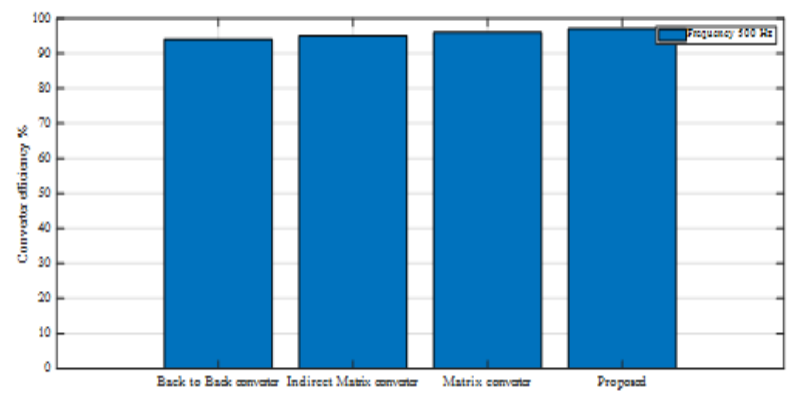

Fig: 4.14 Comparison of Efficiency with existing converters to proposed

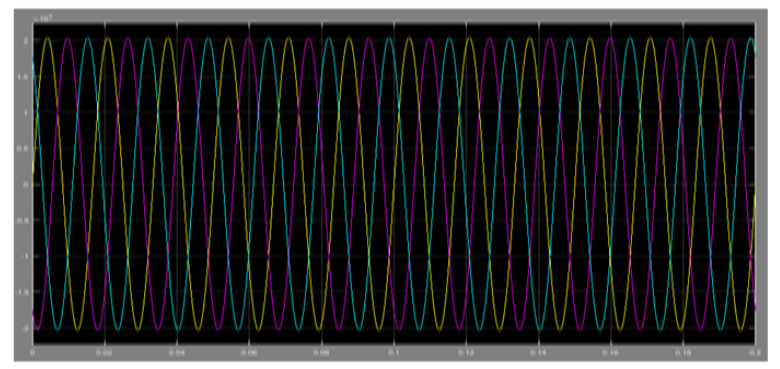

Fig 4.15: The above result is the voltage output obtained from [21]

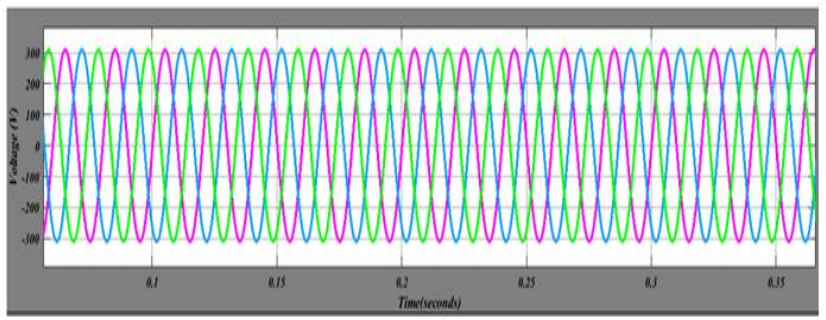

Fig 4.16: The graph above shows the voltage graph obtained as a result of the proposed model
Since the proposed system has followed systematic conversion of generated power source such that power loss is controlled by the bridge type rectifier and subsequently high frequency components and faults currents are mitigated by nonlinear inductor and fault current limiter and finally noise also removed by the cascaded c type filter so it has maintained the voltage stability even when there is high order harmonics is arising. The obtained results has shown that the proposed system has achieved better root mean square error and the mean square error since it has followed a systematic conversion of power generated from the DFIG based wind turbine such that for maintaining the low power loss, it has adapted a bridge type rectifier, for coping with the high frequency components, it has employed nonlinear inductor and for false current as well as noise, it has adapted fault current limiter and the cascaded c type filter respectively, By this way the proposed system has achieved better removal of both low order and high order harmonics.

\section{CONCLUSION}

Harmonic problems such as, abundance warming, increasingly acoustic commotion, torsional vibration of engine shaft, recompense issues in DC engines, and so forth. Existing components have utilized VFD (Variable Frequency Drive) engines and transformer yet these systems has incited engine warming at low speed and prompted control line sounds this prompts corruption in execution of other gear associated with a similar supply is genuinely influenced. Since the proposed framework in this work has considered the accompanying criteria control misfortune, blame current and the high recurrence part and pursued by the orderly change, this framework can battle with the high symphonious bending and kept up the influence quality and the transient soundness of the breeze turbine.

\section{REFERENCES}

1. AncaD.Hansen, Florin Lov, FredgeBlaabjerg and LarH.Hansen, " Review of contemporary Wind Turbine Concepts and their Market Penetration", IEEE Electronics, Vol. 28, pp. 247-263, 2004.

2. VenkataYaramasu, Bin Wu, Paresh C. Sen and Samir Kouro, "High-Power Wind Energy Conversion Systems: State-of-the-Art and Emerging Technologies", IEEE Electronics, Vol. 13, 2014.

3. Zhe Chen, Josep M. Guerrero and FredeBlaabjerg, "A Review of the State of the Art of Power Electronics for Wind Turbines", ", IEEE Electronics, Vol. 24, pp 1859-1875, 2009.

4. Morris Brenna, FedricaFoiadelli, Michaela Lomgo and Dario Zaninelli, "Renewable Energy Impact on Power Quality Performances in Modern Electric Grids", Wseas Transaction on Power System, 2015.

5. F.Blaabjerg, Z. Chen, R. and Teodorescu, F. I, "Power Electronics in Wind Turbine Systems", IEEE Electronics, 2006.

6. MdRabiul Islam, YouguangGuo and Jianguo Zhu, "Power converters for wind turbines: Current and future development", IEEE Electronics, 2007.

7. R. C. da Silva and Malik E. Elbuluk, "Fundamentals of Power Electronics", Power Electronics for Renewable and 
Distributed Energy System,2013.

8. MdRabiul Islam, YouguangGuo, and Jianguo Zhu, "Power converters for wind turbines: Current and future development", 2007.

9. YerraSreenivasaRao and A. Jaya Laxmi, "Direct Torque Control of Doubly Fed Induction Generator Based Wind Turbine Under Voltage Dips", International Journal of Advances in Engineering \& Technology, ISSN: 2231-1963, 2012.

10. Yongchang Zhang, Jianguo Zhu, "A Simple Method to Reduce Torque Ripple inDirect Torque-Controlled Permanent-Magnet Synchronous Motor by Using Vectors", IEEE Electronics, 2008.

11. ChayanBhattacharjee and Binoy Krishna Roy,"Advanced fuzzy power extraction control of wind energy conversion system for power quality improvement in a grid tied hybrid generation system", IET Generation, Transmission \& Distribution, ISSN 1751-8687, 2016

12. Ahmed Medjber, AbderrezakGuessoum, HocineBelmili and Adel Mellit,"New neural network and fuzzy logic controllers to monitor maximum power for wind energy conversion system",Energy, pg-137-146, 2016.

13. Himani and RatnaDahiya,"Development of Wind Turbine Emulator for Standalone Wind Energy Conversion System", Proceedings on IEEE,2016.

14. Islam M R, Guo Y G, Zhu J G. A medium frequency transformer with multiple secondary windings for medium voltageconverter based wind turbine power generating systems. Journal of Applied Physics. 2013; 113:17A324-17A324-3

15. El-hawary M E. Principles of Electric Machines with Power Electronic Applications. IEEE Press: A John Wiley \& Sons Inc;2002

16. Hossain, M.Z. and Rahim, N.A., 2018. Recent progress and development on power DC-DC converter topology, control, design and applications: A review. Renewable and Sustainable Energy Reviews, 81, pp.205-230.

17. An, L., Cheng, T. and Lu, D.D.C., 2018. Single-Stage Boost-Integrated Full-Bridge Converter with Simultaneous MPPT, Wide DC Motor Speed Range and Current Ripple Reduction. IEEE Transactions on Industrial Electronics.

18. Frances, A., Asensi, R., García, Ó., Prieto, R. and Uceda, J., 2018. Modeling electronic power converters in smart DC microgrids-An overview. IEEE Transactions on Smart Grid, 9(6), pp.6274-6287.

19. Takahashi I, Noguchi T. A new quick-response and high-efficiency control strategy of an induction motor. IEEE Transactions on Industry Applications. 1986; IA-22:820-827

20. Malesani L, Tenti P. A novel hysteresis control method for current-controlled voltage-source PWM inverters with constantmodulation frequency. IEEE Transactions on Industry Applications. 1990; 26:88-92.

21. Noguchi T, Tomiki H, Kondo S, Takahashi I. Direct power control of PWM converter without power-source voltage sensors. IEEE Transactions on Industry Applications. 1998; 34:473-479.

22. Li S, Haskew T A, Swatloski R P, Gathings W. Optimal and direct-current vector control of direct drive PMSG wind turbine. IEEE Transactions on Power Electronics. 2012; 27:2325-2337.

23. Shahbazi M, Poure P, Saadate S, Zolghadri M R. FPGA-based reconfigurable control for fault-tolerant back to back converter without redundancy. IEEE Transactions on Industrial Electronics. 2013; 60:3360-3371.

24. Mr. G. Devadasu, Dr. M. Sushama "Design and Control of Interline Unified Power Quality Conditioner using Fuzzy Logic" National Conference on Converging Technologies beyond 2020 (CTB-2020), April 2011, International Journal of Applied Engineering Research
(IJAER), Vol6 Issue 5, ISSN: 0973-4562 pp. 575-586.. 